\title{
A QUALIFICAÇÃO DO CONHECIMENTO NO TRIBUNAL DO JÚRI
}

\section{THE KNOWLEDGE QUALIFICATION IN JURY COURT}

\author{
Amanda Freiberger Miranda ${ }^{1}$ \\ Marize Mattos Dall'Aglio Hattnher ${ }^{2}$ \\ Universidade Estadual Paulista "Júlio de Mesquita Filho" (UNESP)
}

\begin{abstract}
RESUMO
As categorias qualificacionais da modalidade epistêmica e da evidencialidade são analisadas no contexto específico das sessões do tribunal do júri. Indicadoras das avaliações do falante em relação ao valor de verdade das proposições e das indicações da fonte do conteúdo proposicional veiculado, essas qualificações são especialmente produtivas na construção das estratégias persuasivas. Nesse contexto, analisamos a expressão lexical dessas categorias segundo a classificação dos subtipos evidenciais e modais proposta pela Gramática Discursivo-Funcional (HENGEVELD; MACKENZIE, 2008; HENGEVELD; HATTNHER, 2015), a fim de verificar a funcionalidade da indicação da fonte do conhecimento e do valor de verdade dos enunciados na fala dos advogados de defesa e de acusação, defendendo a hipótese de que os evidenciais também podem funcionar como asseveradores ou atenuadores do valor de verdade, função tipicamente modal.
\end{abstract}

PALAVRAS-CHAVE: evidencialidade; modalidade epistêmica; Gramática Discursivo-Funcional.

\begin{abstract}
The qualificational categories of epistemic modality and evidentiality are analyzed in the specific context of jury sessions. Indicating the speaker's evaluation with respect to the truth value of the propositions and the source of the information expressed, these qualifications are specially productive in the construction of persuasive strategies. In this context, we analyze the lexical expression of these categories according to the classification of the evidentials and modals subtypes proposed by the Functional Discursive Grammar (HENGEVELD; MACKENZIE, 2008; HENGEVELD; HATTNHER, 2015) in order to verify the functionality of the indication of evidences in the prosecutor and the defense's speech, defending the hypothesis that evidentials can also function as reinforcement or attenuation of the truth value, a typically modal function.
\end{abstract}

KEYWORDS: evidentiality; epistemic modality; Functional Discursive Grammar.

\section{INTRODUÇÃO}

A evidencialidade e a modalidade epistêmica são categorias que marcam, respectivamente, a fonte da informação e a avaliação do valor de verdade do enunciado e são especialmente produtivas na construção das estratégias persuasivas. Essas categorias, sendo qualificacionais, são analisadas em termos do seu escopo semântico pela Gramática Discursivo-Funcional, doravante

\footnotetext{
${ }^{1}$ Mestranda em Estudos Linguísticos pelo Programa de Pós-Graduação em Estudos Linguísticos da Univerisidade Estuadual Paulista "Júlio de Mesquita Filho" (este trabalho foi financiado pelo CNPq em bolsa PIBIC - 38587) amandafreibergerm@gmail.com

${ }^{2}$ Doutora em Linguística e Língua Portuguesa, Professora do Departamento de Estudos Linguísticos e Literários do Instituto de Biociências, Letras e Ciências Exatas da UNESP e Pesquisadora Nível Pq2 do CNPq (Processo n. 314386/2018-1)-mahattnher@hotmail.com
} 
GDF (HENGEVELD; MACKENZIE, 2008), modelo de gramática que permite uma abordagem estratificada dessas categorias e que será utilizado para a análise aqui empreendida.

A expressão da fonte da informação do enunciado pode ser feita de forma gramatical ou lexical. A análise da expressão gramatical tem sido bastante investigada, segundo diferentes suportes teóricos e em diferentes línguas, sendo crucial o trabalho de Aikhenvald (2004), que faz uma análise tipológica da evidencialidade em mais de 500 línguas. Segundo o suporte teórico da GDF, a expressão gramatical da evidencialidade é analisada por Goméz-Rendón (2006), Hattnher (2013a), Hengeveld e Hattnher (2015), entre outros. A análise da expressão lexical tem sido feita também em várias línguas, especialmente no inglês, sendo fundamental o trabalho de Nuyts (2001), que analisa a subjetividade na expressão da evidencialidade e da modalidade. Na língua portuguesa, língua em que a evidencialidade se expressa majoritariamente pela forma lexical, a GDF foi utilizada por Casseb-Galvão (2011), Ferrari (2012), Kapp-Barboza (2017) especialmente para a análise da verbos evidenciais. Conforme veremos na apresentação do arcabouço teórico, os subtipos de evidencialidade identificados por Hengeveld e Hattnher (2015) a partir da análise de línguas com expressão gramatical da evidencialidade constituirão a base da nossa análise da língua portuguesa.

De acordo com Aikhenvald (2004), a função da evidencialidade é explicitar como o falante adquiriu o conhecimento do que está expressando e qual é a origem desse conhecimento. Apesar de a evidencialidade muitas vezes ser confundida com a modalidade epistêmica, Aikhenvald defende que tal categoria envolve a forma pela qual o enunciador adquire a informação, sem necessariamente envolver o grau de certeza do enunciador sobre a verdade do enunciado. Como aponta Hengeveld (2004), essa indicação da atitude proposicional do enunciador é feita pela categoria modal, estando a modalidade epistêmica relacionada ao que o falante sabe em relação ao mundo real. Apesar de existir uma distinção entre evidencialidade e modalidade epistêmica, Faller (2006) aponta que as duas categorias têm relação, uma vez que o tipo de evidência que o falante tem do enunciado que está proferindo interfere no grau de certeza que ele tem sobre o que está sendo enunciado.

$\mathrm{Na}$ literatura, é comum encontrar autores classificando a evidencialidade como um subtipo da modalidade epistêmica. Dendale e Tasmowski (2001) apresentam três relações entre as noções de evidencialidade e modalidade: disjunção (disjunction), na qual as categorias são vistas como distintas, inclusão (inclusion), na qual uma categoria abrange o espoco semântico da outra, e sobreposição (overlap), na qual as categorias se sobrepõem. Segundo os autores, as diferentes opiniões acerca desse assunto se devem ao fato de que, em diferentes línguas, as marcações de fonte da informação também marcam a atitude e opinião do falante. Alinhados com De Haan (1999), consideramos, neste trabalho, que as duas categorias são distintas.

De acordo com De Haan (1999), a distinção semântica entre a evidencialidade e a modalidade epistêmica se expressa, também, pela relação que estabelecem com a negação: enquanto modais epistêmicos podem ocorrer no escopo da negação, os evidenciais não podem. $O$ linguista também afirma que, embora ambas as categorias qualificacionais apareçam a partir de evidências, elas se relacionam de forma distinta com essas informações. Na modalidade epistêmica, a evidência (o conhecimento) serve de base para a expressão do grau de certeza que o falante tem em relação a seu enunciado, enquanto na evidencialidade, a evidência apenas explicita qual é a fonte da informação veiculada, sem a indicação de certeza ou incerteza do falante.

Buscando analisar os efeitos de sentido resultantes da expressão dessas duas categorias qualificacionais e as eventuais superposições, analisamos o discurso jurídico utilizado em sessões de júri popular, uma vez que, nesse tipo de interação, a fonte da informação e o valor de verdade dos enunciados são fundamentais para a construção da argumentação. Utilizamos, para tanto, um corpus criado por Comparini (2002), composto por transcrições de três sessões de júri do tribunal de Franca, estado de São Paulo. Esse córpus foi escolhido por se tratar de um discurso em que advogado de acusação (A) e advogados de defesa (D) tentam convencer outras pessoas de que estão certos, fazendo assim uso de evidenciais e modais para dar mais credibilidade a suas falas, 
como podemos ver nos exemplos (1) e (2) abaixo, em que são feitos usos de modalizador epistêmico e evidencial respectivamente.

(1) Tenho tempo para proceder mais um pouquinho, mas eu vou parar por aqui, porque tenho certeza que não vamos chegar a esse ponto. (A-I)

(2) ...eu creio que [os jurados] são pessoas que não desprezarão esses argumentos de colocação que farei. (A-II)

No exemplo (1), temos o uso de um modalizador epistêmico de certeza, enquanto no (2), temos um caso de evidencialidade de inferência, que marca conhecimento da informação a partir de um cálculo mental particular, feito de forma subjetiva.

As falas da acusação e da defesa serão analisadas a fim de se verificar i) o papel da evidencialidade e da modalidade epistêmica na construção da persuasão e ii) a relação que a explicitação da fonte da informação tem com a avaliação do valor de verdade da proposição.

Este artigo está organizado da seguinte maneira: na seção 1, apresentamos brevemente o modelo teórico da Gramática Discursivo-Funcional, arcabouço teórico que serve como base para a análise da modalidade epistêmica e da evidencialidade; na seção 2, são apresentados os critérios de análises e a metodologia de investigação utilizados; a seção 3 traz a análise dos usos de evindenciais e modais epistêmicos na fala dos advogados de acusação e defesa em três tribunais de júri e, por fim, na seção 4, são apresentadas as considerações finais.

\section{Arcabouço teórico}

A análise feita nesta pesquisa teve como fundamentação teórica a Gramática DiscursivoFuncional (GDF), de Hengeveld e Mackenzie (2008). A GDF é uma teoria que se encontra entre o formalismo radical e o funcionalismo radical; aproxima-se do formalismo, ao propor uma descrição formalizada do conhecimento da língua e, do funcionalismo, ao entender que o conhecimento da língua é instrumental na comunicação interpessoal.

Segundo Hengeveld e Mackenzie (2008), a GDF é o Componente Gramatical de uma teoria mais ampla de interação verbal que interage com o Componente Conceitual, Componente Contextual e Componente de Saída. O Componente Conceitual é responsável pela cognição, é o lugar onde se origina o que será expresso no Componente Gramatical. O Componente de Saída é responsável pelas expressões acústicas ou escritas produzidas pelo Componente Gramatical. O Componente Contextual abrange o contexto do evento de fala, as relações entre os participantes e a forma do discurso precedente: este componente abrange apenas os aspectos do contexto que têm influência sobre o Contexto Gramatical. 


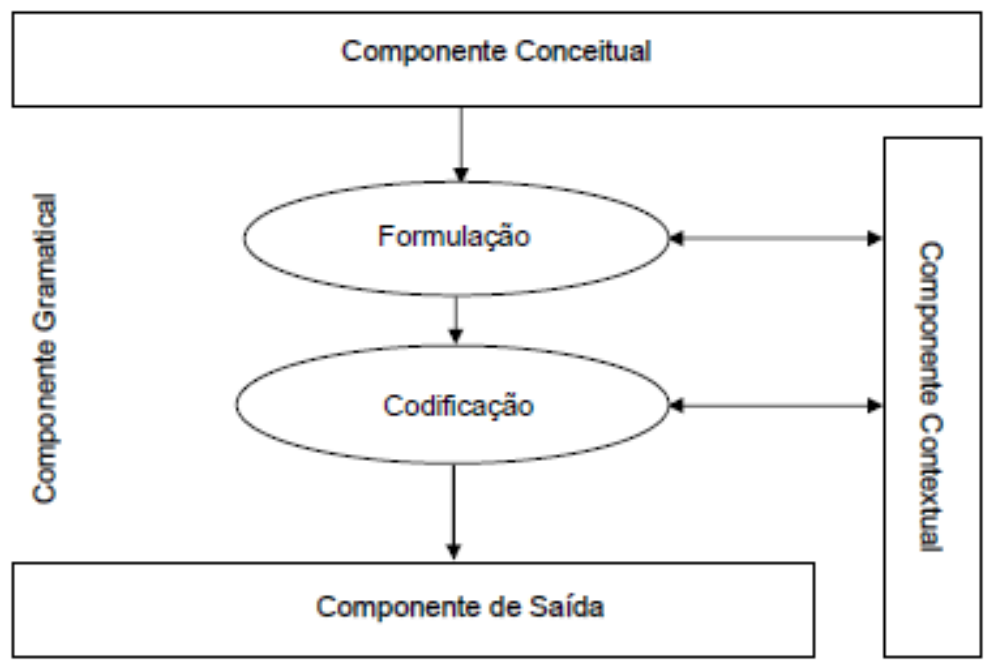

Figura 1 "A GDF como parte de uma teoria mais ampla da interação verbal" retirada de Hengeveld e Mackenzie (2012, p. 44)

Os três componentes apresentados interagem com o Componente Gramatical por meio de operações de Formulação e Codificação (Figura 1). A Formulação está relacionada ao que constitui representações semânticas e pragmáticas válidas em uma língua, enquanto a Codificação está relacionada à conversão das representações semânticas e pragmáticas em representações morfossintáticas e fonológicas (HENGEVELD; MACKENZIE, 2012).

A estrutura da GDF é dividida em quatro níveis que são subdivididos em camadas. Esse modelo constitui-se como uma teoria hierárquica, que apresenta uma organização descendente topdown, que parte do discurso para as unidades menores. Os quatro níveis descritos pela GDF são o Nível Interpessoal, o Nível Representacional, o Nível Morfossintático e o Nível Fonológico. Os níveis Interpessoal e Representacional fazem parte da formulação do evento de fala, e os níveis Morfossintático e Fonológico são os responsáveis pela codificação dos níveis anteriores (figura 2 abaixo).

"O Nível Interpessoal capta todas as distinções de Formulação que dizem respeito à interação entre o Falante e o Ouvinte" (HENGEVELD, MACKENZIE, 2012, p. 51). Este nível está diretamente relacionado à pragmática. As camadas do Nível Interpessoal, em ordem hierárquica decrescente, são as seguintes: Movimento $>$ Ato Discursivo $>$ Ilocução $>$ Falante $>$ Ouvinte $>$ Conteúdo Comunicado $>$ Subato Atributivo $>$ Subato Referencial.

O Nível Representacional trata dos aspectos semânticos das unidades linguísticas. "Enquanto o Nível Interpessoal cuida da evocação, o Nível Representacional é responsável pela designação" (HENGEVELD, MACKENZIE, 2012, p. 54). As camadas do Nível Representacional, em ordem hierarquicamente decrescente, são as seguintes: Conteúdo Proposicional $>$ Episódio $>$ Estado-de-Coisas $>$ Propriedade Configuracional $>$ Propriedade Lexical > Indivíduo.

O Nível Morfossintático, juntamente com o Nível Fonológico, é responsável pela codificação das distinções interpessoais e representacionais. Este nível "trata dos aspectos estruturais de uma unidade linguística”. (HENGEVELD; MACKENZIE, 2012, p. 58). As camadas do Nível Morfossintático, em ordem hierarquicamente decrescente, são as seguintes: Expressão Linguística $>$ Oração $>$ Sintagma $>$ Palavra $>$ Raiz $>$ Afixo.

Na codificação, o Nível Fonológico complementa o Nível Morfossintático. "Ele recebe o input - parte dele já na forma fonêmica - de todos os três outros níveis e fornece o imput para o Componente de Saída" (HENGEVELD, MACKENZIE, 2012, p. 62). A divisão de suas camadas, em ordem hierarquicamente decrescente, é a seguinte: Enunciado $>$ Frase Entonacional $>$ Frase Fonológica $>$ Palavra Fonológica $>$ Pé $>$ Sílaba. 


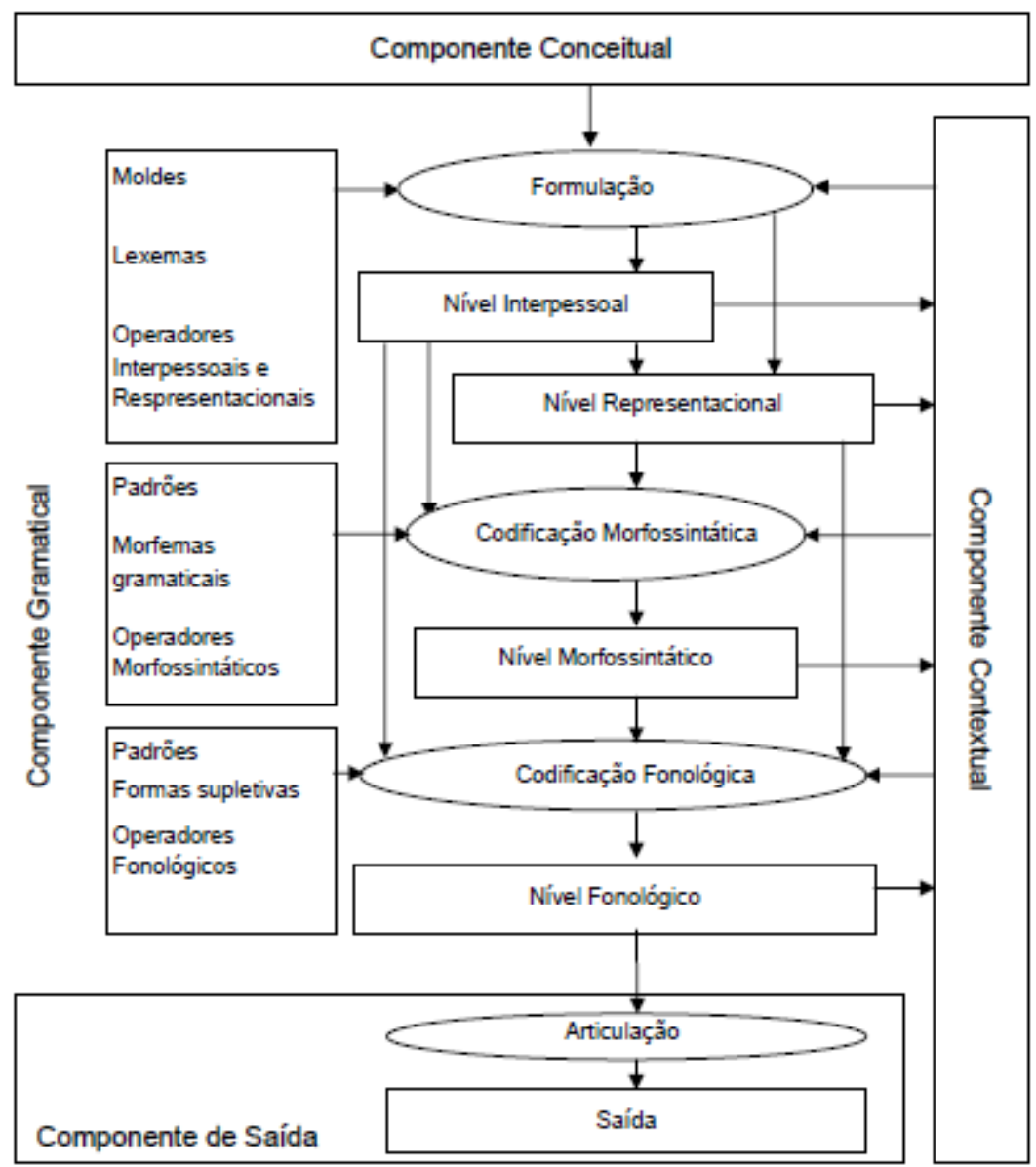

Figura 2 "Esquema Geral da GDF” retirada de Hengeveld e Mackenzie (2012, p. 46)

Como veremos, a modalidade epistêmica atua no Nível Representacional, descrito acima, enquanto a evidencialidade atua tanto no Nível Interpessoal quanto no Nível Representacional.

$\mathrm{Na}$ GDF, as modalidades são descritas segundo a proposta de Hengeveld (2004), que utiliza dois parâmetros semânticos para a classificação dos subtipos modais: o alvo de avaliação (target of evaluation) e o domínio semântico de avaliação (domains of evalutation). No alvo de avaliação o autor diferencia modalidade objetiva de modalidade subjetiva e identifica os seguintes subtipos:

a) Modalidade orientada para o falante: afeta a parte relacional do enunciado expresso por um predicado. Diz respeito à relação entre (propriedades de) um participante em um evento e a realização potencial daquele evento.

b) Modalidade orientada para o evento: afeta a descrição de um evento contina no enunciado, isto é, a parte descritiva de um enunciado. Diz respeito à avaliação objetiva do estatuto de realidade do evento.

c) Modalidade orientada para a proposição: afeta o conteúdo proposicional de um enunciado, isto é, a parte do enunciado que representa a visão e a crença do falante. Diz respeito à especificação do grau de comprometimento do falante com relação à proposição que ele apresenta. (HENGEVELD, 2004, p.1192-1193 - tradução nossa) ${ }^{3}$

3 (a) Participant-oriented modality. This type of modality affects the relational part of the utterance as expressed by a predicateand concerns the relation between (properties of) a participant in an event and the potential realization of that event (cf. Foley \& Van Valin 1984: 215). (b) Event-oriented modality. This type of modality affects the event description contained within the utterance, i.e the descriptive part of an utterance, and concerns the objective assessment of the actuality status of the event. (c) Proposition-oriented modality. This type of modality affects the 
Em dominio semântico de avaliação, o autor apresenta o campo semântico dentro do qual a avaliação é feita e identifica os seguintes subtipos:

a) modalidade facultativa: relacionada a capacidades intrínsecas ou adquiridas. [...] John é capaz de nadar. (Habilidade: Facultativa)

b) modalidade deôntica: relacionada ao que é (legal, social e moralmente) permissível. [...] John tem de nadar. (Obrigação: Deôntica)

c) Modalidade volitiva; relacionada ao que é desejável. [...]John preferiria não nadar. (Desejo: Volitiva)

d) Modalidade epistêmica: relacionada ao que é sabido em relação ao mundo real. [...] John deve estar nadando. (Possibilidade: Epistêmica)

e) Modalidade evidencial:relacionada com a fonte da informação contida em uma sentença. [...] Eu acho que John está nadando. (Inferência: evidencial) (HENGEVELD, 2004, p.1193 - tradução nossa) ${ }^{4}$

Essa categorização é utilizada por Hengeveld e Mackenzie (2008) na inserção da categoria nos níveis e camadas da GDF. Os subtipos modais identificados por Hengeveld (2004) estão alocados em quatro diferentes camadas de acordo com seu escopo. As modalidades deôntica, facultativa e volitiva orientadas para o falante se encontram alojadas na camada da Propriedade Configuracional, as modalidades deôntica, facultativa e volitiva orientadas para o evento, no Estado de Coisas, a modalidade epistêmica orientada para o episódio, no Episódio, e a modalidade epistêmica orientada para a proposição, na Proposição, como aponta a Tabela 1 a seguir:

\begin{tabular}{|c|c|c|c|c|}
\hline NÍVEL & \multicolumn{4}{|c|}{ REPRESENTACIONAL } \\
\hline CAMANDA & $\mathrm{f}$ & $\mathrm{e}$ & ep & $p$ \\
\hline $\begin{array}{l}\text { SUBCATEGORIA } \\
\text { MODAL }\end{array}$ & $\begin{array}{c}\text { Deôntica, } \\
\text { Facultativa e } \\
\text { Volitiva } \\
\text { orientada para o } \\
\text { participante }\end{array}$ & $\begin{array}{c}\text { Deôntica, } \\
\text { Facultativa e } \\
\text { Volitiva } \\
\text { orietanda para o } \\
\text { evento }\end{array}$ & $\begin{array}{c}\text { Epistêmica } \\
\text { orientada para o } \\
\text { episódio } \\
\text { (objetiva) }\end{array}$ & $\begin{array}{c}\text { Epistêmica } \\
\text { orientada para a } \\
\text { proposição } \\
\text { (subjetiva) }\end{array}$ \\
\hline
\end{tabular}

Tabela 1: "Distribuição dos subtipos modais segundo a arquitetura da GDF" retirada de Hattnher (2013b, p. 18)

Na classificação de Hengeveld (2004), a evidencialidade é considerada como um subtipo de modalidade, posição que será revista em Hengeveld e Dall'Aglio-Hattnher (2015). A partir do aparato teórico da GDF, e analisando línguas com expressão gramatical da evidencialidade, esses autores definiram quatro subtipos evidenciais. Essa classificação foi confirmada para o português, língua com expressão majoritariamente lexical da evidencialidade, por Hattnher (2018, p. 101 -102):

i. Reportatividade, que opera na camada do Conteúdo Comunicado no Nível Interpessoal, indica que o falante não está expressando seu próprio material cognitivo, mas está passando adiante a opinião de outros: Estudos feitos dizem que o produto não é cancerígeno. (internet)

ii. A Inferência, que opera na camada do Conteúdo Proposicional no Nível Representacional, indica que o Conteúdo Proposicional é inferido pelo falante com

propositional content of an utterance, i.e. the part of the utterance representing the speaker's views and beliefs, and concerns the specification of the degree of commitment of the speaker towards the proposition he is presenting.

4 (a) Facultative modality is concerned with intrinsic or acquired capacities. [...]John is able to swim. (Ability: Facultative) (b) Deontic modality is concerned with what is (legally, socially, morally) permissible. [...]John has to swim. (Obligation: Deontic) (c) Volitive modality is concerned with what is desirable. [...] John would rather not swim.(Wanting: Volitive) (d) Epistemic modality is concerned with what is known about the actual world. [...] John may be swimming. (Possibility: Epistemic) (e) Evidential modality is concerned with the source of the information contained in a sentence. [...] John will be swimming.(Inference: Evidential) 
base em seu conhecimento prévio. Em princípio, parece que a definição de renda se apresenta bastante clara e precisa. (internet)

iii. Dedução, que opera no nível do Episódio e indica que a ocorrência de um episódio é deduzida pelo falante com base em uma evidência disponível; o falante não testemunha o próprio episódio, mas ele é capaz de deduzir sua ocorrência a partir da percepção de alguma evidência resultante: Estive olhando as fotos da Camila e percebi que ela varia os filtros de acordo com a cor da foto. (internet)

iv. Percepção de Evento, que opera na camada do Estado-de- Coisas no Nível Representacional e indica se um evento foi ou não testemunhado pelo falante: Não estava frio, mas um pouco de vento trazia a brisa do mar. Senti o cheiro entrar nas minhas narinas. (internet)

Nessa proposta, a distinção essencial deixa de ser a diferença entre evidencialidade direta e indireta, proposta por Willet (1988), e passa a ser a distinção entre o nível de organização do enunciado em que a evidencialidade se aloja, no Interpessoal (pragmático) ou no Representacional (semântico).

No esquema geral da GDF, esses subtipos evidenciais estão alojados em diferentes camadas, sendo a inferência, a dedução e a percepção de evento categorias do Nível Representacional, e a reportatividade do Nível Interpessoal, sendo esse o sutipo evidencial que apresenta o escopo mais alto, uma vez que contém o enunciado de outro falante. Distribuindo os quatro subtipos evidenciais de acordo com a GDF, temos a tabela 2, em que a perpepção de evento está alojada na camada mais baixa, o Estado de Coisas, a dedução, no Episódio, a inferência, na Proposição e a reportatividade, no Conteúdo Comunicado, no Nível Interpessoal.

\begin{tabular}{|l|c|c|c|c|}
\hline NÍVEL & \multicolumn{3}{|c|}{ REPRESENTACIONAL } & INTERPESSOAL \\
\hline CAMADA & e & ep & $\mathrm{p}$ & $\mathrm{C}$ \\
\hline $\begin{array}{l}\text { SUBCATEGORIA } \\
\text { EVIDENCIAL }\end{array}$ & $\begin{array}{c}\text { percepção de } \\
\text { evento }\end{array}$ & dedução & inferência & reportatividade \\
\hline
\end{tabular}

Tabela 2: "Distribuição dos subtipos evidenciais segundo a arquitetura da GDF" retirada de Hattnher (2013b, p. 20)

Conforme se verá na próxima seção, esses subtipos evidenciais serão utilizados na análise aqui empreendida, buscando eventuais intesecções com os subtipos modais alojados nas mesmas camadas.

\section{Corpus e critérios de análise}

O corpus utilizado nesta pesquisa foi criado por Comparini (2002) e é composto pela transcrição de três sessões de júri que ocorreram em 2001, na cidade de Franca, estado de São Paulo. Comparini (2002), com autorização do juiz responsável, gravou em áudio e vídeo as falas de juízes, advogados de defesa e de acusação. As gravações foram posteriormente transcritas, e, nas transcrições, foram omitidos os nomes de todos os envolvidos. Nas sessões gravadas, atuaram três advogados de defesa diferentes, o mesmo juiz e o mesmo advogado de acusação. Em nosso trabalho, analisamos apenas as falas dos advogados de defesa e acusação, uma vez que as falas do juiz não apresentam estratégias de persuasão que levam ao uso de modais epistêmicos e evidenciais. A escolha desse corpus se deve ao fato de, nesse tipo de discurso, as estratégias persuasivas dos enunciadores se assentarem no uso de modais epistêmicos e de evidenciais para reforçar a credibilidade de seus argumentos.

As ocorrências de modais epistêmicos e evidenciais foram analisadas contrastando-se as falas dos advogados de defesa e de acusação, uma vez que interessa a essa pesquisa analisar a funcionalidade do modal epistêmico e do evidencial na construção de argumentos supostamente antagônicos em respeito ao valor de verdade e às fontes das informações utilizadas. A tabela a seguir apresenta todos os critérios utilizados na análise: 


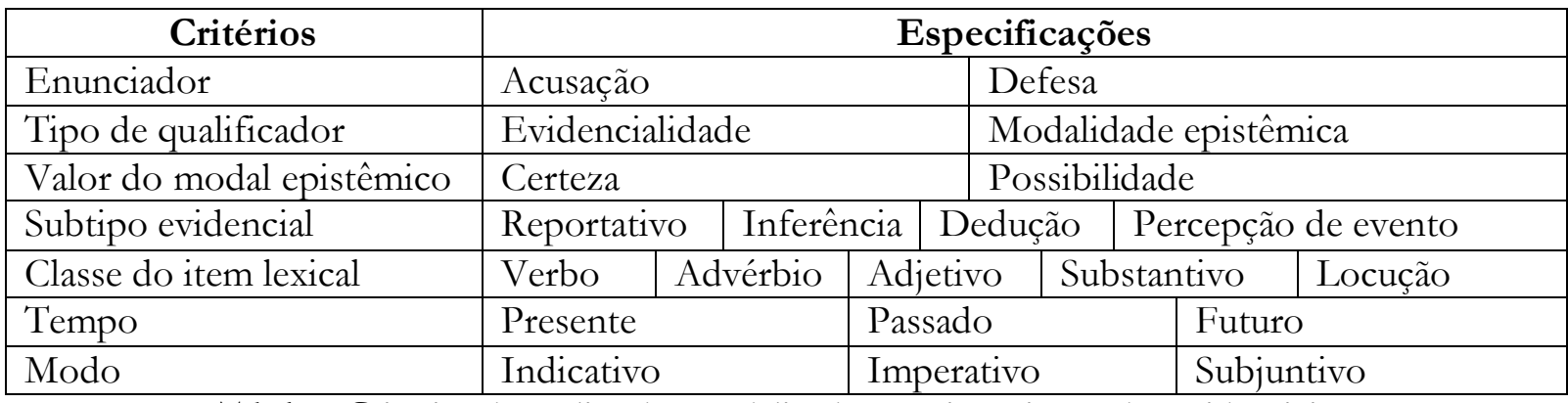

Tabela 3: Critérios de análise dos modalizadores epistêmicos e dos evidenciais

\section{Discussão dos dados}

Nas ocorrências que serão analisadas, a identificação das sessões (I, II ou III) encontra-se ao final, junto com a identificação da posição do advogado, de acusação (A) ou defesa (D). O total de ocorrências encontradas na fala de cada um é apresentado na Tabela 4:

\begin{tabular}{|c|c|c|c|}
\hline & Acusação & Defesa & TOTAL \\
\hline Evidencial & $103-43,5 \%$ & $97-54 \%$ & $200-48 \%$ \\
\hline Modal & $134-56,5 \%$ & $83-46 \%$ & $217-52 \%$ \\
\hline TOTAL & $237-100 \%$ & $180-100 \%$ & $417-100 \%$ \\
\hline
\end{tabular}

Tabela 4: Total de ocorrências de modais e evidenciais no corpus

A partir da tabela 4, é possível notar que a acusação utilizou mais modalizadores epistêmicos (56,5\%) do que evidenciais, enquanto a defesa utilizou mais evidenciais (54\%). Ao longo da análise, procuraremos caracterizar esse comportamento, considerando o tipo de fonte e o grau de certeza acionados pelos advogados, conforme se verá a seguir.

\subsection{Usos dos modais epistêmicos}

Os tipos de modais epistêmicos utilizados pelos enunciadores representativos de cada posição argumentativa (defesa e acusação) são apresentados na Tabela 5:

\begin{tabular}{|c|c|c|c|}
\hline & Acusação & Defesa & TOTAL \\
\hline Certeza & $108-80,6 \%$ & $62-74,70 \%$ & $170-78,34 \%$ \\
\hline Possibilidade & $26-19,4 \%$ & $21-25,30 \%$ & $47-21,66 \%$ \\
\hline TOTAL & $134-100 \%$ & $83-100 \%$ & $217-100 \%$ \\
\hline
\end{tabular}

Tabela 5: Tipo de modal

Ao analisar os tipos de modais epistêmicos que as partes usaram, pudemos notar que o modal de certeza foi preferido, sendo o recurso mais utilizado para construir a credibilidade necessária tanto para as falas da defesa como da acusação.

(3) Eu não tenho dúvida de que houve uma tentativa de homicídio (A-I)

(4) Ele não foi lá, com certeza, para pedir para parar o barulho, ele foi lá para fazer acabar o barulho. (D-I)

O modal de certeza ainda foi usado como forma de persuadir o júri a votar a favor do que cada parte defendia, como nos exemplos a seguir: 
(5) Tenho tempo para proceder mais um pouquinho, mas eu vou parar por aqui, porque tenho certeza que não vamos chegar a esse ponto, porque quando quesitados a cerca da suposta agressão, vão afastar. Tenho certeza disso. (A-I)

(6) Então Srs., eu tenho a convicção plena que vocês refletirão muito, e muito mesmo, quando forem depositar os seus votos justamente ao primeiro quesito, quando forem perguntados se foi J. que matou o seu filho. (D-III)

Os valores de incerteza foram utilizados para duas funções: i) para instaurar dúvidas sobre o dizer do outro, como se pode observar nas ocorrências abaixo:

(7) Ora, como seria possível, na versão da acusada, que a vítima, utilizando-se de um pedaço de pau, primeiramente tentasse enforcá-la?! (A-I)

(8) Não dá para se afirmar que ela desistiu apenas porque...não tem nem motivo para falar que... ela desistiu por quê? (D-I)

e ii) para construir casos hipotéticos:

(9) Esse inquérito aqui foi instaurado porque a vítima, realmente, antes dos fatos, provavelmente já estava sofrendo maus tratos e agressões por parte dos acusados. (A-III)

(10) se desse uma faca ou um revólver para o Sr. e o Sr. se sentisse coagido, talvez descarregaria o revólver. (D-I)

Considerando-se que as oportunidades de fala foram idênticas para acusação e defesa, pode-se atribuir o maior número absoluto do modal de certeza pela acusação ao fato de que, nos três júris analisados, os réus eram claramente culpados, tanto que foram condenados. Nessas circunstâncias, o papel do advogado de acusação é garantir que a verdade seja explicitada, cabendo ao advogado de defesa garantir que a pena, já esperada, seja aplicada com justiça, buscando atenuar os agravantes da verdade. Esse fator pode ter contribuído também para o menor número de modais utilizados em geral pela defesa, que optou por usar mais evidenciais e argumentar, principalmente, com base no que foi dito pelo réu e pelas testemunhas, seja para confirmar ou para contestar os relatos.

Quanto à forma de expressão, observa-se um uso bastante semelhante entre defesa e acusação, que usaram preferencialmente advérbios tanto para a expressão da certeza quanto da possibilidade, como se vê na tabela 6:

\begin{tabular}{|c|c|c|c|c|c|}
\hline \multirow{2}{*}{} & \multicolumn{2}{|c|}{ Acusação } & \multicolumn{2}{c|}{ Defesa } & \multirow{2}{*}{ Total } \\
\cline { 2 - 5 } & Certeza & possibilidade & certeza & possibilidade & \\
\hline Advérbio & $69-63,89 \%$ & $12-46,16 \%$ & $27-43,55 \%$ & $10-47,62 \%$ & $118-54,38 \%$ \\
\hline Substantivo & $35-32,41 \%$ & $5-19,23 \%$ & $24-38,71 \%$ & $2-9,52 \%$ & $66-30,41 \%$ \\
\hline Adjetivo & $4-3,70 \%$ & $5-19,23 \%$ & $9-14,52 \%$ & $6-28,57 \%$ & $24-11,06 \%$ \\
\hline Verbo & $0-0 \%$ & $4-15,38 \%$ & $2-3,22 \%$ & $3-14,29 \%$ & $9-4,15 \%$ \\
\hline Total & $108-$ & $26-100 \%$ & $62-100 \%$ & 21 & $217-100 \%$ \\
\cline { 2 - 5 } & \multicolumn{3}{|c|}{170} & \multicolumn{2}{|c|}{47} \\
\hline
\end{tabular}

Tabela 6: Forma de expressão dos modais

A acusação usou predominantemente advérbios para a expressão modal de certeza $(63,89 \%)$, como no exemplo (11). O uso de cada classe de palavras foi mais parecido entre acusação e defesa com os modais de possibilidade, diferenciando-se apenas no uso de adjetivo e substantivo, 
em que a defesa usou mais adjetivos (12) e a acusação fez uso igual de adjetivos (13) e substantivos (14).

(11) Ora, se O. realmente naquele dia tivesse chegado brigando, chutando, etc. e tal (A-I)

(12) A cartucheira não acharam a cartucheira e a vítima não foi baleada. Se ela tivesse sido baleada pelo menos na ponta do pé, era prova, claro! (D-II)

(13) Bom, então, já podemos verificar, e é bastante claro isso, a perspectiva e a idéia que dominava o adolescente: - Olha, vamos jogar tudo nas costas de A (A-II)

(14) Tenho tempo para proceder mais um pouquinho, mas eu vou parar por aqui, porque tenho certeza que não vamos chegar a esse ponto (A-I)

As locuções não foram usadas para expressar valor modal. Entretanto, substantivos (15) e adjetivos (16) apareceram apenas na expressão dessa categoria. A defesa fez um uso maior de adjetivos $(18,07 \%)$ quando comparado ao uso da acusação $(6,72 \%)$.

(15) Eu não tenho dúvida de que houve uma tentativa de homicídio (A-I)

(16) A cartucheira não acharam a cartucheira e a vítima não foi baleada. Se ela tivesse sido baleada pelo menos na ponta do pé, era prova, claro! (D-II)

Chama a atenção o fato de os verbos modais, forma mais típica de expressão da modalidade, serem pouco utilizados tanto pela defesa como pela acusação. Isso certamente se deve ao fato de, entre os epistêmicos, os auxiliares modais servirem à indicação de possibilidade, valor pouco frequente na construção argumentativa das duas partes:

(17) Com a redução, deve cair para uns quatro anos, (D-I)

(18) Eu acho que é ele que deve ter alguma coisa contra o réu, de maneira a querer prejudicá-lo, (A-II)

Com relação ao tempo da oração modal, todas as ocorrências apareceram no presente do indicativo, como é típico dessa qualificação, que expressa uma avaliação do falante com relação ao valor de verdade do seu enunciado, sendo, portanto, atrelada ao momento da enunciação.

\subsection{Usos dos evidenciais}

Em relação ao tipo de evidencial, observa-se um comportamento bastante semelhante da defesa e da acusação, que utilizaram com maior frequência a evidencialidade reportativa:

\begin{tabular}{|c|c|c|c|}
\hline & Acusação & Defesa & TOTAL \\
\hline Dedução & $3-2,9 \%$ & $7-7,2 \%$ & $10-5 \%$ \\
\hline Inferência & $12-11,7 \%$ & $10-10,3 \%$ & $22-11 \%$ \\
\hline Reportativo & $88-85,4 \%$ & $80-82,5 \%$ & $168-84 \%$ \\
\hline TOTAL & $103-100 \%$ & $97-100 \%$ & $200-100 \%$ \\
\hline
\end{tabular}

Tabela 7: Tipo de evidencial

Os evidenciais foram analisados de acordo com a classificação dos subtipos evidenciais sugerida por Hengeveld e Dall'Aglio Hattnher (2015): dedução, inferência, reportativo e percepção de evento. No corpus, não ocorreram casos de percepção de evento, isso porque a defesa e a acusação não estavam presentes nos momentos dos crimes e não podem ter ouvido, escutado ou visto nada que aconteceu para usar como argumento. O reportativo foi o subtipo mais utilizado por ambas as partes, os depoimentos dos réus, das vítimas e das testemunhas eram retomados para dar força à argumentação, como nos exemplos a seguir: 
(19) Todos os irmãos, a testemunha I, a testemunha J. disseram que ele toma remédio controlado, que ele fica nervoso, mas que ele não é agressivo. (D-I)

(20) A vítima se sentindo prejudicada e perturbada foi até o local dos fatos e, encontrando a acusada, segundo ela, já entrou no local chutando as panelas com um pedaço de pau na mão e passou a enforcá-la. (A-I)

A inferência é utilizada para expressar que o enunciador é a fonte da informação e que chegou àquela informação por meio de seus conhecimentos anteriores. No júri, os advogados de defesa e acusação utilizaram esse recurso para expressar a fonte da informação e relativizar o valor de verdade com verbos como "acho" e "creio", como nos exemplos que seguem:

(21) Eu acho que, na verdade, o que está errado é que a vítima M que aqui está presente, que reconheceu o acusado aqui, olhando para ele e dizendo (A-II)

(22) Creio que não, creio que vocês, talvez, se assim agirem, refletirão e já não haverá como se arrepender, porque o voto é secreto e uma vez só. (D-III)

O subtipo menos encontrado foi a dedução (5\%), e na grande maioria desses casos a forma de expressão foi o advérbio "obviamente", com exceção de uma ocorrência com o advérbio "evidentemente".

(23) Obviamente que ele caiu na realidade, sentiu que o que ele fez foi uma tremenda ignorância, pois admitir culpa de alguém, simplesmente porque ele achou que o amor era mais importante (D-III)

(24) No entanto, são fotos da necropsia e que tiveram alguma indício de que tivesse o réu, o acusado colado fita na boca da criança, evidentemente que lá também estaria designado algum relatório sobre isso, porque quando a gente cola fica marca. (DIII)

Em ambos os casos, a evidência é colocada como disponível igualmente para o enunciador e os enunciatários, uma vez que os eventos são colocados como fatos observáveis, como óbvios e evidentes.

Em relação às formas de expressão da evidencialidade, observa-se uma especialização de algumas classes de palavras, como se vê na tabela abaixo:

\begin{tabular}{|c|c|c|c|c|c|c|}
\hline & \multicolumn{2}{|c|}{ Dedução } & \multicolumn{2}{c|}{ Inferência } & \multicolumn{2}{c|}{ Reportativo } \\
\hline & Acusação & Defesa & Acusação & Defesa & Acusação & Defesa \\
\hline Advérbio & $3-100 \%$ & $7-100 \%$ & $0-0 \%$ & $0-0 \%$ & $0-0 \%$ & $0-0 \%$ \\
\hline Verbo & $0-0 \%$ & $0-0 \%$ & $12-100 \%$ & $10-100 \%$ & $70-79,5 \%$ & $74-92,5 \%$ \\
\hline Loucução & $0-0 \%$ & $0-0 \%$ & $0-0 \%$ & $0-0 \%$ & $18-20,5 \%$ & $6-7,5 \%$ \\
\hline TOTAL & $3-100 \%$ & $7-100 \%$ & $12-100 \%$ & $10-100 \%$ & $88-100 \%$ & $80-100 \%$ \\
\cline { 2 - 7 } & \multicolumn{3}{|c|}{10} & \multicolumn{3}{c|}{22} \\
\hline
\end{tabular}

Tabela 8: Classe do item evidencialzas

Como se vê, a dedução foi expressa exclusivamente por meio de advérbios, como em (25) e (26):

(25) Chamou a polícia. Ia sumir com o corpo? Obviamente que isso ia vir à tona uma hora ou outra, familiares, como a própria irmã de N., que se viam sempre preocupados com a criança (A-III) 
(26) Vocês, sem que o acusado pudesse ter o direito de se manifestar em sua defesa, obviamente já o teriam condenado, senão, até à pena de morte, pelo fato de ele ter sido acusado de ter matado seu próprio filho. (D-III)

A inferência também foi expressa exclusivamente por uma única classe de palavras, os verbos plenos:

(27) Eu acho que é ele que deve ter alguma coisa contra o réu, de maneira a querer prejudicá-lo. (A-II)

(28) Vocês terão plena consciência de condená-lo, convictos de que as provas que foram trazidas aos Srs. são verdadeiras? Creio que não, creio que vocês, talvez, se as sim agirem, refletirão e já não haverá como se arrepender, porque o voto é secreto e uma vez só. (D-III)

Já a evidência reportativa foi expressa majoritariamente por verbos e (29) e (30) e, também, por meio de locuções (31) e (32):

(29) Ela afirmou que no dia dos fatos, juntamente com seu amásio, estava na cozinha, ali do imóvel. (A-I)

(30) Ele disse que viu a faca, mas no momento da facada ele nem se quer estava lá. (D-I)

(31) Segundo J.R., os fatos não teriam ocorrido exatamente dessa forma. (A-I)

(32) Ele só foi lá porque, como consta nos autos, infelizmente, é uma família desestruturada. (D-I)

Observa-se que a acusação fez um uso maior de locuções evidenciais $(20,5 \%)$ do que a defesa (7,5\%). Esse recurso, no entanto, foi utilizado para diferentes funções, servindo à indicação clara da fonte da informação pela acusação, que era nomeada claramente na locução, como em (31), e servindo à indicação de uma fonte mais inespecífica pela defesa, como em (32):

O tempo das orações evidenciais também foi analisado, e os resultados confirmam as características de cada subtipo dessa qualificação, como se vê na tabela 9, que traz apenas os subtipos evidenciais expressos por verbos:

\begin{tabular}{|c|c|c|c|c|c|}
\hline & \multicolumn{2}{|c|}{ Inferência } & \multicolumn{2}{|c|}{ Reportativo } & \multirow[t]{2}{*}{ TOTAL } \\
\hline & Acusação & Defesa & Acusação & Defesa & \\
\hline Presente & $12-100 \%$ & $10-100 \%$ & $13-23,64 \%$ & $15-22,39 \%$ & $50-34,73 \%$ \\
\hline Pretérito imperfeito & $0-0 \%$ & $0-0 \%$ & $5-9,09 \%$ & $0-0 \%$ & $5-3,47 \%$ \\
\hline $\begin{array}{c}\text { Pretérito perfeito } \\
\text { simples }\end{array}$ & $0-0 \%$ & $0-0 \%$ & $37-67,27 \%$ & $50-74,63 \%$ & $87-60,42 \%$ \\
\hline $\begin{array}{l}\text { Pretérito perfeito } \\
\text { composto }\end{array}$ & $0-0 \%$ & $0-0 \%$ & $0-0 \%$ & $1-1,49 \%$ & $1-0,69 \%$ \\
\hline $\begin{array}{l}\text { Pretérito mais-que- } \\
\text { perfeito composto }\end{array}$ & $0-0 \%$ & $0-0 \%$ & $0-0 \%$ & $1-1,49 \%$ & $1-0,69 \%$ \\
\hline TOTAL & $12-100 \%$ & $10-100 \%$ & $55-100 \%$ & $67-100 \%$ & $144-100 \%$ \\
\hline
\end{tabular}

Tabela 9: Tempo do verbo evidencial 
Como se vê, a inferência, que tem como referência o momento da enunciação, é utilizada exclusivamente no tempo presente. Já a evidencialidade reportativa só não ocorre no tempo futuro, uma vez que é logicamente impossível reportar um evento ainda não ocorrido. No entanto, o falante pode marcar como reportado um evento que tenha ocorrência presente ou passada.

A maioria dos verbos evidenciais usados pela defesa e pela acusação ocorreram no pretérito perfeito simples, como no exemplo (33) e (34):

(33) Algazarras essas, brigas essas, que foram ouvidas pela testemunha I., que depois, tanto na fase policial quanto em juízo, disse que houve realmente uma briga. (A-I)

(34) Ela chegou aqui e disse que a faca estava com ela e que desferiu os golpes. (D-I)

\subsection{Coocorrências entre modais e evidenciais}

Além de ocorrências distintas de evidenciais e modais, o corpus foi composto por coocorrências das duas categorias, como mostram os exemplos a seguir:

(35) O interrogado esclarece que realmente participou do crime (A-III)

(36) Ele receberá uma pena, que imagino eu [...] possivelmente será beneficiado pelo regime aberto. (A-II)

Essas coocorrências são especialmente importante por confirmarem a distinção entre evidencialidade e modalidade epistêmica, uma vez que não é possível a coocorrência de duas expressões de uma mesma categoria semântica. No entanto, é nesses casos de coocorrência que se observa um interessante efeito que resulta da somatória dos sentidos da indicação da fonte da informação e da indicação da avaliação do valor de verdade da proposição.

Quando as duas qualificações vão na mesma direção, seus sentidos se somam e obtém-se o reforço desse valor. É o que acontece em (36) acima, em que a subjetividade da fonte da informação assumida como uma inferência do falante (imagino eu) reforça a incerteza da ocorrência do estado-de-coisas qualificado epistemicamente como possível. O mesmo acontece em (35), em que tanto a fonte definida (o interrogado) quanto a asseveração de certeza (realmente) reforçam o valor de verdade da afirmação.

Quando as duas qualificações vão em direções opostas, obtém-se um jogo bastante interessante, como se vê em:

(37) Eu acho que, na verdade, o que está errado é que a vítima $M$ que aqui está presente, [...] é ele que está mentindo. (A-II)

Nessa ocorrência, o uso do evidencial de inferência marca que a fonte da informação é o próprio falante. Para atenuar os efeitos da subjetividade dessa qualificação (eu acho), o advogado de acusação qualifica seu enunciado como certo (na verdade).

O que se observa é que, nos casos de coocorrência, tanto a evidencialidade foi utilizada para reforçar o valor de verdade da afirmação, em uma função prototípica da modalidade epistêmica, quanto a modalidade epistêmica foi utilizada para atenuar o efeito de sentido de subjetividade expresso pelo evidencial de inferência.

\section{CONSIDERAÇÕES FINAIS}

A análise da atuação da evidencialidade e da modalidade epistêmica na fala de enunciadores que ocupam posições antagônicas, como é o caso dos advogados de defesa e acusação, buscou verificar a funcionalidade dessas categorias na construção da argumentação. A hipótese defendida foi a de que, a depender do tipo de fonte de informação veiculada, os evidenciais também podem atuar como asseveradores ou atenuadores do valor de verdade, função tipicamente modal. 
$\mathrm{Na}$ análise dos dados, observou-se que as duas partes fizeram uso parecido dos qualificacionais, embora a acusação tenha recorrido mais à modalidade epistêmica do que a defesa. Os evidenciais foram acionados para fundamentação de um argumento e para constatação de um evento posto como verdadeiro pelo acusado, pela vítima ou pelas testemunhas. A Defesa, que não podia asseverar a inocência dos acusados da forma que a acusação asseverava a culpa, recorreu mais à categoria da evidencialidade. A acusação, por sua vez, que estava em uma posição mais favorável para utilizar frases de certeza, uma vez que em todos os casos analisados o réu foi condenado e era culpado, recorreu com mais frequência à categoria de modalidade epistêmica. Considerando que não era a intenção de nenhuma das partes gerar dúvidas, o modal epistêmico de possibilidade foi evitado por ambos os lados.

Nos casos de coocorrência, a evidencialidade foi usada para reforçar o valor de verdade expresso pelo modal, e a modalidade epistêmica foi usada para atenuar o efeito de incerteza do evidencial de inferência. Esses resultados confirmam que a intersecção entre inferência e modalidade epistêmica, atestada nas línguas com expressão gramatical de tais categorias, também se mostra presente na expressão lexical dessas categorias em português.

A despeito das especificidades das suas funções, tanto a indicação evidencial da fonte da informação quanto a indicação modal epistêmica da atitude que o falante assume com relação ao valor de verdade da sua proposição atuam na construção da assertividade do enunciador. Essa superposição de valores na qualificação do conhecimento poderia ainda ser investigada na expressão da evidencialidade reportativa, para se verificar em que medida a credibilidade da fonte da informação interfere na percepção do valor de verdade do conteúdo comunicado. Uma investigação futura dessa hipótese demandaria uma análise de outro tipo de interação como, por exemplo, a que se dá por meio do discurso científico, lugar natural da construção da argumentação baseada em conhecimento reportado.

\section{REFERÊNCIAS BIBLIOGRÁFICAS}

AIKENVALD, A. Y. Evidentiality. Oxford: Oxford University Press, 2004.

COMPARINI, A. M. P. A modaliz̧ação deôntica no discurso jurídico. 2002. 101 f. Dissertação (Mestrado em Estudos Linguísticos) - Universidade Estadual Paulista, São José do Rio Preto. 2002.

CASSEB-GALVÃO, V. C. Gramática discursivo-funcional e teoria da gramaticalização: revisitando os usos de [diski] no português brasileiro. Filol. linguíst. port., n. 13(2), p. 305-335, 2011

DE HAAN, F. Evidentiality and epistemic modality: setting boundaries. Southwest Journal of Linguistics, v. 18, p.83-101, 1999.

DENDALE, P.; TASMOWSKI, L. Introduction: Evidentiality and Related Notions. Journal of Pragmatics, v.33, p.339-348, 2001

FALLER, M. Evidentiality and epistemic modality at the Semantics/ Pragmatics interface. 2006. Disponível em: www. semanticsarchive.net. Acesso em: 05 jan. 2007.

FERRARI, V. V. Verbos de percepção em construções evidenciais de acordo com o modelo da gramática discursivo-funcional. Revista Linguística, v.8 (1), p.100-112, 2012.

FOLEY, W. A.; VAN VALIN, R. D. Functional Syntax and Universal Grammar. Cambridge: Cambridge University Press, 1984

GOMÉZ-RENDÓN, J. Interpersonal Aspects of Evidentiality in Ecuadorian Quechua. Amsterdã: ACLC Working Papers 1. p. 37-50, 2006.

HATTNHER, M. M. D. A. The interaction between tense and evidentials of event perception and deduction in Brazilian Native languages. In: MACKENZIE, J. L.; OLBERTZ, H. (Ed.) Casebook in Functional Discourse Grammar. 1ed. Amsterdam: John Benjamins, p. 39-66, 2013 a. 
HATTNHER, M. M. D. A. Modalidade epistêmica e evidencialidade: especificidades e intersecções na abordagem da Gramática Discursivo-Funcional. São José do Rio Preto: Relatório científico (Processo FAPESP 2013/19313-5), 2013b.

HATTNHER, M. M. D. A. A expressão lexical da evidencialidade: reflexões sobre a dedução e a percepção de evento. Entrepalavras, [S.1.], v. 8, n. 6esp, p. 98-111, set. 2018. Disponível em: <http://www.entrepalavras.ufc.br/revista/index.php/Revista/article/view/1244>. Acesso em: 20 out. 2018.

HENGEVELD, K. Mood and modality. In: Geert Booij, Christian Lehmann \& Joachim Mugdan eds, Morphology: A bandbook on inflection and word formation, v. 2, 1190-1202. Berlin: Mouton de Gruyter, 2004.

HENGEVELD, K.; HATTNHER, M.M.D.A. Four types of evidentiality. Linguistics, v. 53, p. 479524, 2015.

HENGEVELD, K.; MACKENZIE, L. Functional Discourse Grammar: A typologically-based theory of language structure. Oxford: Oxford University Press, 2008.

Gramática Discursivo-Funcional. In: SOUZA, E. R. F. Funcionalismo linguístico: novas tendências teóricas. Tradução de Marize Mattos Dall'Aglio-Hattnher. São Paulo: Contexto, 2012, p. 43-85.

KAPP-BARBOZA, A. M. M. Usos do verbo saber e a expressão da evidencialidade no português brasileiro. 2017. 165 f. Tese (Doutorado em Estudos Linguísticos) - Instituto de Biociências, Letras e Ciência Exatas, Universidade Estadual Paulista "Júlio de Mesquita Filho", São José do Rio Preto, 2017.

NUYTS, J. Subjectivity as an evidential dimension in epistemic modal expressions. Journal of Pragmatics, v. 33, n. 3, p. 383-400, 2001.

WILLET, T. A cross-linguistic survey of the grammaticalization of evidentiality. Studies in Language, v.12, 1, p. 51-97, 1988.

Submetido em 30/11/2018

Aceito em 23/04/2019

Publicado em 11/06/2019 